\title{
Integrating Team Laboratory Experiments Into a Senior Biochemical Engineering Course
}

\author{
Christopher S. Brazel \\ Department of Chemical Engineering \\ The University of Alabama \\ Tuscaloosa, AL 35487-0203
}

\begin{abstract}
\end{abstract}
A laboratory supplement to a senior biochemical engineering course was developed to improve teaming skills and expose chemical engineering students to nontraditional industries, such as food, pharmaceuticals, biomedical engineering, and bioprocessing. This diversity in the chemical engineering curriculum prepares students for a career that may include one of these industries. The course is taught as a 3-credit lecture class, and with funds awarded by the Camille and Henry Dreyfus Foundation, four laboratory experiments were developed to involve the students in active learning and allow them to work directly with biological compounds and cells. The experiments emphasize some of the main points taught in lectures, namely in the areas of enzyme kinetics, fermentations, cell growth/nutrient supply, and bioseparations. Each of the student teams give one presentation on theory as the subject fits into the regularly scheduled lectures, and complete experiments before submitting a final report and giving a second presentation on experimental methods and results. The experiments give students a chance to work with equipment and techniques appropriate for the biotechnology industry, including hemocytometry, electrophoresis, centrifuges, incubators, dissolved oxygen probes, ultrafiltration membranes, and a spectrophotometer. Further information on this course is available on-line at www.bama.ua.edu/ cbrazel/BioChELab.htm, along with links to many biotechnology resources.

Introduction

The University of Alabama's chemical engineering department offers a biochemical engineering laboratory as part of an elective course to give students opportunities in the expanding markets of pharmaceuticals and biotechnology. These two sectors have shown strong growth in employment of chemical engineers ${ }^{1}$, and with the recent growth in technological breakthroughs related to biology and medicine, engineers must be trained to work with biochemicals for process design and scale up for production of such products as new drugs, biomaterials, bio-based fuels and enzymes ${ }^{2}$. In the next several years, chemical engineers will be increasingly exposed to biochemical processes in auxiliary roles, such as biochemical sensors for on-line monitoring of chemical reactors and the use of microorganisms in environmental bioremediation. With the advancements made in biological research in the past decade ${ }^{3}$, chemical engineers need to be trained to work with different chemical entities, and understand the importance of proteins, enzymes, polysaccharides and cellular bodies so that the research can be translated into marketable products, be used effectively to optimize production and reduce environmental waste, and keep our nation's economy strong. 
Chemical engineering education in the US has done exceedingly well at training new engineers for the necessary jobs of the current economy, through excellence in developing problem solving skills, training students in basic scientific and technological theories and applying that knowledge and those concepts to difficult and diverse problems. In the past decade, chemical engineering programs have trained new engineers whose skills are adaptable and not tied into any particular industry (such as petrochemicals). This technological diversity is part of the strength of many new research ideas, and chemical engineers being educated in 2002 must be prepared for new opportunities that will arise during the next 20-30 years, especially those derived from environmental sciences as well as health and biological sciences, including biomedicine, bioprocessing, and microbiology. With increases in the biological and environmental engineering sciences budgets at the National Science Foundation and the National Institutes of Health in recent years ${ }^{4}$, the research will soon make bio-based process engineering common practice and will be required for all chemical engineering students. The interface between biology/biochemistry and chemical engineering requires little additional basic science, but exposure of students to these topics may open up doors to achieve new products such as better sensing devices for poison monitors, optimizing fermentation and cellular bioreactors, and creation of environmentally-sound energy alternatives.

The biochemical engineering class, at its simplest, introduces concepts related to biochemistry and brings together much of the chemical engineering curriculum so that students can see an important application of the knowledge gained in the course of their B.S. education. On perhaps a more global level, the biochemical engineering class can be a platform for chemical engineering students who wish to (or decide later to) pursue advanced education through medical school, dental school, graduate school in biomedical/biochemical related topics, and other careers that they may not be aware of prior to the exposure they gain in biochemical engineering. This course provides some of the basics needed for further growth in the biologyrelated engineering fields, including introductions to biochemistry and cellular biology. The course combines these areas with familiar engineering topics, such as reactor design and reaction kinetics, so that the focus is on applying engineering and not strictly learning specific behaviors at the cellular or molecular levels.

\section{Background}

Biochemical engineering is offered as an elective class in many chemical engineering departments, and has been recognized for at least 20 years as an emerging area important for training process engineers and other chemical engineering students. Although a multitude of quality textbooks exist on this subject, the texts primarily used are limited to Bailey and Ollis 5 and Shuler and Kargi ${ }^{6}$, which has recently been revised with a 2001 edition. Topics typically covered in biochemical engineering courses can be designed to meet a class' interest and needs, but the majority of common subjects are listed in Table 1. Although the texts mentioned above describe biochemistry, reaction kinetics, bioreactor design, etc., very well, simple lectures in addition to the textbooks often leave students without a good physical understanding of the materials, equipment and other components used in biological systems and how they differ from traditional chemical engineering unit operations. 


\begin{tabular}{|c|}
\hline Table 1. Topics Covered in Biochemical Engineering Lectures \\
\hline Biomolecules: Biochemistry of proteins, polysaccharides, lipids and nucleic acids \\
Cellular Microbiology \\
Enzyme Action \\
Enzyme kinetics, analysis and inhibition \\
Bioenergetics and Metabolic processes \\
Aerobic and Anaerobic Respiration \\
Fermentation \\
Cell Growth Phases \\
Monod Kinetics of Cell Growth \\
Batch vs. Continuous Production \\
Stoichiometry \\
Mass Transfer \\
Bioseparations \\
Biomaterials/Tissue Engineering \\
Introduction to Genetics \\
Bioremediation \\
Ethics in Bioengineering \\
Drug and Gene Delivery
\end{tabular}

In addition to offering biochemical engineering elective courses, a number of chemical engineering programs have adopted biochemical engineering laboratory experiments into their curriculum, either through the design of unit operations experiments to enhance the senior engineering laboratory course, or through methods similar to the one described herein ${ }^{7}$, where experiments are tied in directly to the biochemical engineering lecture course.

The range of chemical engineering-related topics (Table 2) that rely on biochemical engineering as an introductory course continue to expand, even as some chemical engineering departments, such as those at Cornell University and the University of Illinois, are adopting name changes to 'chemical and biomolecular engineering' and the like. Research in bio-related areas has increased substantially over the past decade, and when many of these laboratory advances are brought up to pilot and production scale, chemical engineers knowledgeable of biochemical processes will be needed to run these processes economically.

\begin{tabular}{|ccc|}
\hline Table 2. Emerging Topics Related to Biochemical Engineering \\
\hline Tissue Culture & Genetically-Modified Crops & Biomaterials \\
Drug Delivery & Tissue Engineering & Cloning \\
Bioterrorism & Biosensing & Gene Therapy \\
Biophotonics & Bioremediation & \\
\hline
\end{tabular}


Objectives

The biochemical engineering course has three main purposes for the students who enroll:

(1) provide an avenue to expand the breadth of technical knowledge and apply concepts learned in the chemical engineering curriculum to biochemic al areas,

(2) allow specialization for students interested in pursuing careers in pharmaceutics, medicine or research, and

(3) expose students interested in chemical sciences to the emerging presence of chemical engineers in biological and biochemical processes.

The objectives of including a laboratory component for this class were to:

(1) building teamwork skills on a single long-term experiment

(2) building communication skills for presenting both theory and experimental findings through presentations,

(3) familiarizing chemical engineering students with the equipment, methods and materials associated with bioprocesses,

(4) determining appropriate methodological design and experimental parameters needed to meet a specific objective, and

(5) collecting and analyzing data to compare to theory.

Methods

Incorporating team-based laboratory experiments into an existing course required a focus on the fundamental concepts being covered and developing projects that emphasized both theory and applications. Since some class time is used for the projects, each of the topics was selected so that its place in the curriculum could be presented directly by the students. After selecting appropriate projects, funding was secured to provide equipment and supplies, and general experimental procedures were developed (and tested by undergraduate laboratory assistants prior to the course offering). The projects were selected to emphasize four main course topics: enzyme kinetics, cell growth, anaerobic fermentations, and bioseparations.

Selection of Projects

The four projects (Table 3) were designed to demonstrate the application of biochemical engineering theories, and to fit with the major topics covered in lectures.

\begin{tabular}{|c|}
\hline Table 3. Topics for Team Projects \\
\hline $\begin{array}{c}\text { Kinetics of Substrate-Trypsin Reactions as a Function of pH, } \\
\text { Substrate Concentration, Inhibition and Immobilization }\end{array}$ \\
\hline $\begin{array}{c}\text { Batch Cell Growth of Saccharomyces Cerevisae as a Function } \\
\text { of Temperature, Carbon Source, and Nutrient Supply }\end{array}$ \\
\hline $\begin{array}{c}\text { Oxygen Consumption and Acidification during Fermentation } \\
\text { of High Fructose Corn Syrup using Saccharomyces Cerevisae }\end{array}$ \\
\hline $\begin{array}{c}\text { Separation and Purification of an Invertase from Yeast by } \\
\text { Sonication, Centrifugation, Ultrafiltration as Analyzed by } \\
\text { Polyacrylamide Gel Electrophoresis }\end{array}$ \\
\hline
\end{tabular}




\section{Enzyme Kinetics}

Enzyme kinetics was discussed at length in class, and the team assigned this project was given a topic with a narrow focus for the theory presentation: immobilization of enzymes. This allowed the introduction of enzyme concepts in detail during lectures, and helped the group deliver a presentation that followed the lectures quite naturally. Experiments were formulated to study the effects of substrate concentration, $\mathrm{pH}$, inhibition and immobilization on reaction velocities. A color-changing reaction was selected so that the product formation could be monitored using a visible spectrophotometer. The reactions were quenched using acetic acid, and absorbance measured to correlate product concentrations using Beer's Law. pH was controlled using buffer capsules, which allowed buffers to be made easily in the laboratory. One problem noted here was bubble interference with absorbance readings when buffers containing carbonates were used. Data were analyzed and compared to Michaelis-Menten theory.

\section{Batch Cell Growth}

Saccharomyces cerevisae, a common yeast, was used in batch cell growth reactors. The cell count was measured on a haemocytometer and used to calibrate the absorbance at $600 \mathrm{~nm}$ on a spectrophotometer. The experiment was designed to study the growth curve during the lag and exponential growth phases as a function of carbon source (glucose vs. sucrose vs. glycerol), temperature and concentration of carbon source. The cells were grown in suspended culture, using flasks mixed using a shaker temperature bath. This project required extended laboratory experimental times, as the lag phases continued for a number of hours. Exponential growth was compared to Monod kinetics to determine the effect of experimental conditions on specific growth rates.

\section{Fermentation}

This topic included a presentation of the history of fermentations, along with the significance of metabolic pathways for the production of anaerobic fermentation products. Alcohol fermentation was carried out for a period of 2 weeks, with dissolved oxygen and $\mathrm{pH}$ data collected over the course of the fermentation to verify the exponential growth phase and subsequent anaerobic operation of the fermentation. The production of carbon dioxide was also monitored, using a bubble counter, which was attached to the fermenter as the only gas-phase exit available. The fermentation was run twice, with different starting carbon sources (high fructose corn syrup, which allowed faster transition to the anaerobic phase, and glucose, which first had to be converted to fructose before consumption by the yeast). One experimental recommendation for this project would be to run trials separately to measure (1) dissolved oxygen and $\mathrm{pH}$ versus (2) carbon dioxide production. It is recommended that $\mathrm{CO}_{2}$ generation rates be determined during a separate fermentation, when no sampling is done, as the positive pressure responsible for $\mathrm{CO}_{2}$ escape through the bubble counter was lost when samples were removed. 
Separation and Purification

The theory presented on separation and purification covered a number of separation techniques common to chemical engineering, and demonstrated the applicability of these techniques to biological systems. Much of the theory was focused on techniques more common in biosystems: chromatography, ultrafiltration, and electrophoresis. Experimentally, the project involved growing yeast cells, and isolating invertase from the cell walls. The separation and purification steps followed several paths, including two methods to break the cell walls: chemical (using lyticase) and ultrasonic; the enzyme was concentrated using centrifugation, and ultrafiltration was used to isolate species with molecular weights above 25,000 and below 100,000 . The products isolated at various stages of purification were kept and analyzed by polyacrylamide gel electrophoresis, using a 4-20\% gradient gel, which was useful in separating components with a wide range of molecular weights. Molecular weight standards were run at the same time as the samples to provide a baseline to analyze the contents of commercially available invertase compared to that isolated in class.

Procurement of equipment and materials

Equipment was procured in the months prior to the fall semester, with the help of two laboratory assistants, who also served to calibrate equipment and run test experiments. Major equipment and supplies that were needed for this laboratory (Table 4) were either available or purchased through funds awarded by a Dreyfus Foundation grant.

\section{Table 4. Major Equipment and Chemicals Used in the Course}
1. 5 gallon Fermenter
2. Bubble Counter
3. $\mathrm{pH}$ Meter
4. Dissolved Oxygen Probe
5. Incubating Oven
6. Visible Spectrophotometer
7. Optical Microscope
8. Haemocytometer
9. Electrophoresis Unit (horizontal- vertical recommended)
10. Centrifuge
11. Vortex Mixer
12. Shaker Bath
13. Autoclave

\section{Chemicals included:}

acetic acid (for quenching the enzyme reactions), pre-formed

polyacrylamide gradient gels, $\mathrm{N}$-a-benzoyl-DL-arginine-pnitroanilide (trypsin substrate), coomassie brilliant blue G250 (for staining the electrophoresis gel), sodium dodecyl sulfate (surfactant for electrophoresis), D-glucose, glycerol, lyticase (chemical agent to break yeast walls to extract invertase), peptone, molecular weight marker kit (standards for electrophoresis), high fructose corn syrup, sucrose, trisglycine buffer, trypsin, trypsin inhibitor, acrylamide (for immobilization), and yeast extract 
Initial testing prior to class

As this was a new laboratory in chemical engineering, much of the initial work included specifying and purchasing equipment, supplies and chemicals, creating an inventory database, and testing experimental procedures. Two undergraduate laboratory assistants helped with calibration and initial testing of equipment and development of general procedures for autoclave, haemocytometry, and the operation of other equipment. This was important to reduce the likelihood of surprises during the course.

The Semester: Carrying out the Plan

With one of the goals of this laboratory being to introduce long-term experiments, students were required to work in the laboratory for extended periods, which is distinctly different from typical undergraduate laboratories, and this laboratory was not listed with specific times. Therefore, it was necessary to describe the expectations early in the semester, so that the students would 'buy-in' to the concept of the laboratory and be able to carry out the experiments. This was done at the beginning of the semester and again as the topics were discussed, so that student comments such as those described by Sharfstein and Relue ${ }^{7}$ that the lab time was unexpected or inadequate could be avoided.

\section{Selection of Teams}

Class members were allowed to select a topic based on their interest, and the groups were matched by their preferences and available schedules. Because the lab experiments were significantly different than the pre-set variety taught in typical freshman and sophomore level courses, an important factor in assigning teams was selecting those students who could work together. The first consideration was times available during the week, and the second consideration was the duration of individual experiments so that at least one student would be available to monitor the progress of the experiment over an extended period. A half-page description of each project, listing methods used, and the expected time involved were given to the class prior to project selection. This ensured that the students had advanced knowledge of the opportunities available. Groups were assigned according to student preference and time availability for the group to work together. A flowchart of activities related to the laboratory projects is shown in Figure 1.

The group project involved a number of steps, and included four evaluation points: 2 papers and 2 presentations, one each for the theory and experimental portions of the project. Since one of the stated objectives was to improve technical communication skills, a handout of writing and presentation tips (Appendix Table A1) was distributed prior to the first presentations, and $10-20 \%$ of the grade on each paper/presentation was awarded on technical communication skills. Other important steps in the project are detailed below. 
Figure 1. Flowchart of Project Activities

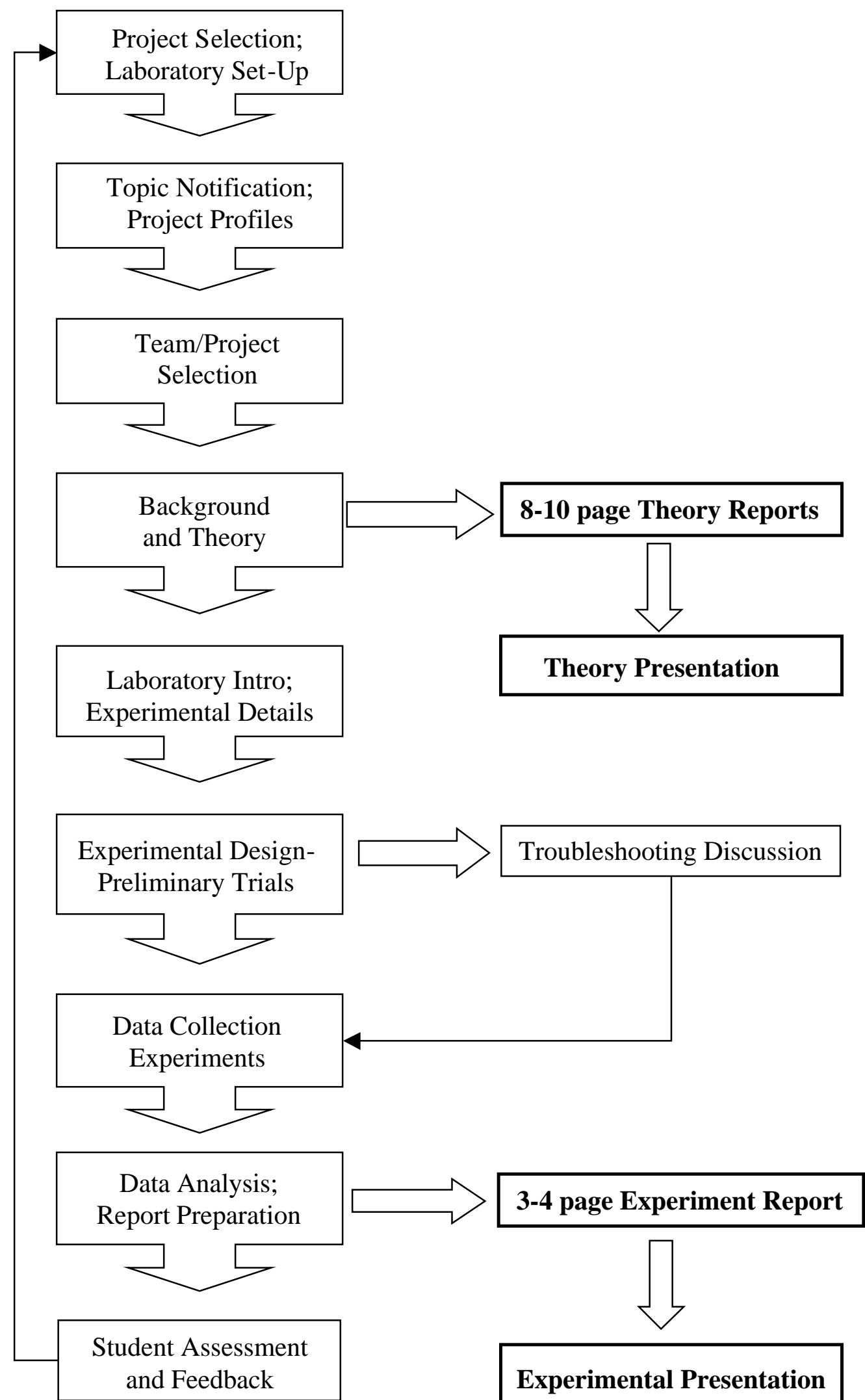


Meeting to Discuss Experimental Work and Introduce Lab

After completion of the theory presentations, the groups were given details on the experimental portion of the team projects. Two-to-three page introductions were handed out for each of the four projects, which detailed the objectives, methods and procedures, and outlined the expected results, without giving specific experimental design or data collection information. These were left for the students to decipher during preliminary experiments, followed by a troubleshooting session to ensure that the needed supplies were available, the methods would work, and the experimental design was adequate. During the introduction phase, the laboratory layout and equipment instructions were explained in 1-hour meetings with each group.

\section{Preliminary Experiments and Troubleshooting}

As with most scientific labs, especially any involving the development of new methods and processes, the initial experiments were very important. All four groups ran preliminary experiments to familiarize themselves with the laboratory techniques, and then had informal meetings with the instructor to troubleshoot a variety of problems. The most frequent problem was with data collection: what measurements to take and how often, and when to know the experiment is done. After these meetings, the students could continue testing out the various experimental trials of each project.

\section{Group Experimental Presentations}

At the end of the semester, each group gave a final presentation covering their experimental procedures, data collection and analysis. Since this was a first-time offering, a large portion of the project scores were based not entirely on the data collected, but thoughtful recommendations on how to improve the experiments so that better data could be collected in further experiments.

\section{Results of Laboratory Experiments}

Sample experimental results from each of the four projects are included in the Appendix (Figures A1 through A4). The enzyme-substrate reaction was carried out as a function of $\mathrm{pH}$, substrate concentration, presence of an inhibitor, and immobilization of trypsin. Figure A1 shows the influence of substrate concentration on the product formation profiles, confirming for high substrate concentrations the Michaelis-Menten Equation is adequate, but conclusions could not be drawn from lower substrate concentrations, since not enough data were collected at early times to determine a steady-state reaction velocity. Figure A2 shows the cell growth curves for Saccharomyces cerevisae as a function of the fed carbon source, its concentration, and the temperature of the shaker bath. Results confirm behavior discussed in class, such as the stoichiometry of carbon sources, the Arrhenius behavior of cell growth with respect to temperature, and the phases of cell growth. The dissolved oxygen profile measured in an anaerobic fermentation showed the phase where oxygen was consumed during exponential growth, followed by an extended period of zero oxygen content (Figure A3). Finally, electrophoresis runs were able to confirm the presence of various fractions of invertase when compared to commercially available invertase (Figure A4). One recommendation from this experiment would be to concentrate the purified invertase prior to running the electrophoresis analysis, since the lanes with the purified samples were barely detectable. 
Feedback

Getting adequate feedback on the success of the course was important for re-designing the biochemical engineering laboratory for the next offering, so informal questions about recommendations for improvement were supplemented by a course survey that could be turned in directly to the instructor, or anonymously in the department office (see Appendix Figure A5).

Remarkably, even though some of the groups worked long hours on the experimental projects, the feedback was overwhelmingly positive about the hands-on laboratory experience, and the recommendation was to reduce the theory portion of the projects. Many of the recommendations were especially important in narrowing the scope of the experiments for future classes, so that the students can be better prepared to collect good data. As for ensuring good theory presentations, reducing the scope of some of the topics (if only for the theory presentation) would be helpful. Specifically, the separations and purification group could focus on only the methods of separation that would be used experimentally, instead of all possible separation techniques; also, the cell growth group could focus only on the Monod equation or a smaller portion of the topic, after bioreactors are introduced in class.

Conclusions and Recommendations

A new laboratory at the University of Alabama was developed for chemical engineering students taking the biochemical engineering elective class. This laboratory was used to conduct four experiments, all covering a time period of approximately 3 months, and done in groups of three students. The students presented theory related to their topic and designed experiments to test that theory, while learning the intricacies of working with biological components.

Other recommendations include modifying both laboratory experiments and project design. One laboratory improvement would be to use a vertical (instead of horizontal) electrophoresis unit, as many pre-poured gradient gels are commercially available, and the separation will be easier to conduct. The project design can be improved specifically by (1) reducing the scope of the theory papers, so that students don't get overwhelmed by the amount of information on some of the general topics, and (2) requiring preliminary experiments earlier in the semester and the submission of an experimental design plan prior to allowing students to complete experimental work. The second recommendation is aimed at ensuring that time spent in the laboratory is more useful and productive, and that more accurate data can be collected for analysis and discussion.

\section{Acknowledgements}

The financial support of the Camille and Henry Dreyfus Foundation for this laboratory through a Special Grant in the Chemical Sciences is gratefully acknowledged. Additionally, the support of laboratory assistants Matthew F. Garcia, J. Brent Jones and Kimberly R. Brooks was greatly appreciated and helped the lab run smoothly during its first offering. 
References

1. AIChE Employment Survey, 1999, www.aiche.org.

2. Thayer, A. "Challenges of a Biobased Economy," Chem. Eng. News 78 no. 22 (2000) 40.

3. Rouhi, A.M. "Biomaterials Body Shop: Diverse Approaches to Diverse Human Needs," Chem. Eng. News 78 no. 26 (2000) 133-141.

4. Hanson, D.J., B. Hileman, C. Hogue, J. Johnson, J.R. Long, and W. Schulz, "Clinton Pushes for R\&D Jump: Clinton's final budget raises R\&D funds for most agencies, expands multiagency initiatives to meet national goals," Chem. Eng. News $\mathbf{7 8}$ no 8 (2000) 18.

5. Bailey, J.E. and D.F. Ollis, Biochemical Engineering Fundamentals, McGraw-Hill, New York, 1986.

6. Shuler, M.L. and F. Kargi, Bioprocess Engineering: Basic Concepts, Prentice Hall, Englewood Cliffs, NJ, 1992.

7. Sharfstein, S. and P. Relue, "Biotechnology and Bioprocessing Laboratory for Chemical Engineering and Bioengineering," Proceed. Amer. Soc. Eng. Educ. Ann. Conf. (2001).

CHRISTOPHER S. BRAZEL is an assistant professor of chemical engineering at the University of Alabama. He teaches biochemical engineering, heat transfer and polymer materials engineering classes. Prior to joining UA in 1999, he was a research engineer in the microencapsulation section at Southwest Research Institute, San Antonio, TX. He earned his B.S. ChE at Texas A\&M and Ph.D. at Purdue and leads a research program in drug delivery. 
Appendix

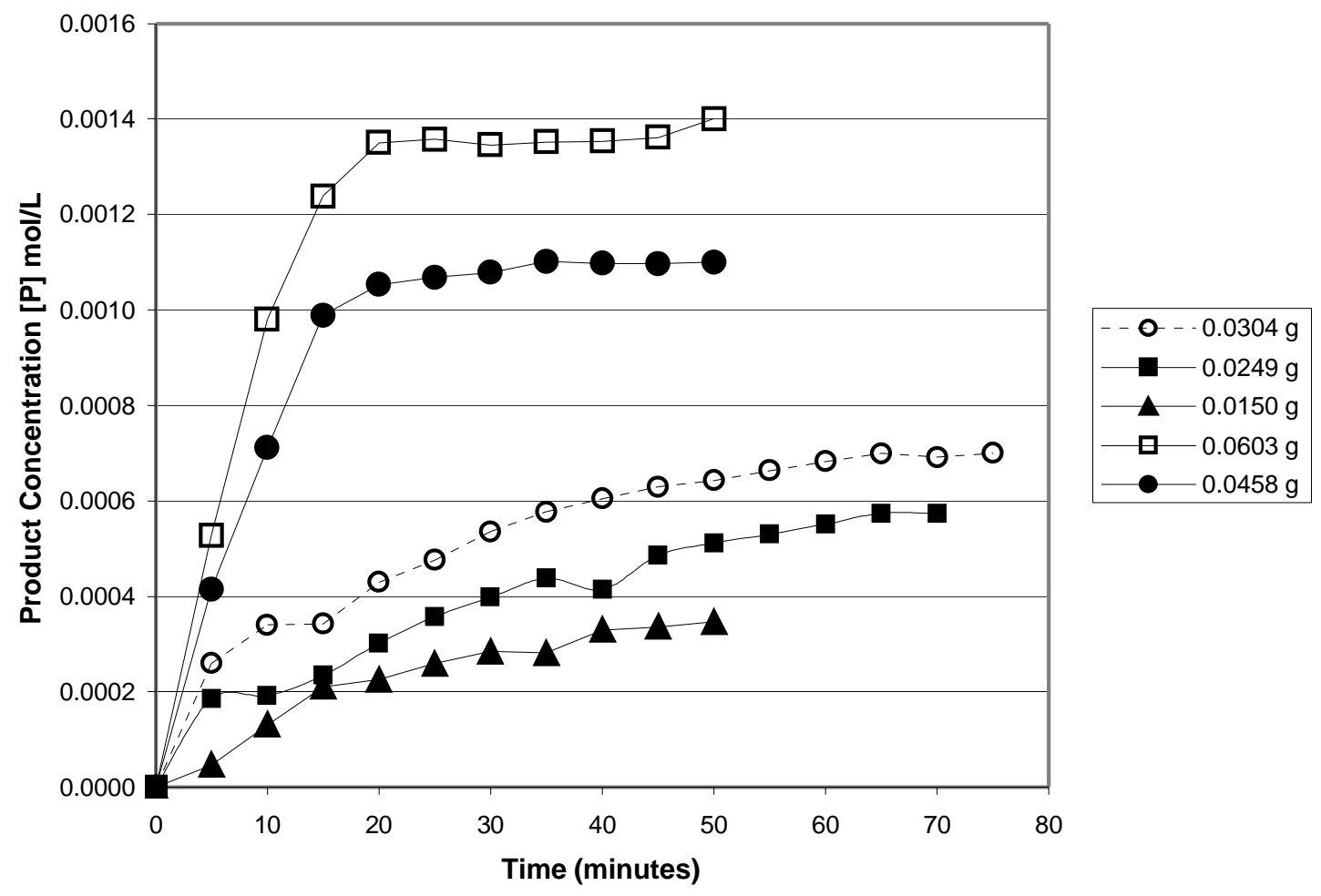

Figure A1. Sample Experimental Results for Enzymatic Reactions as a Function of Substrate Concentration at $30{ }^{\circ} \mathrm{C}$. 


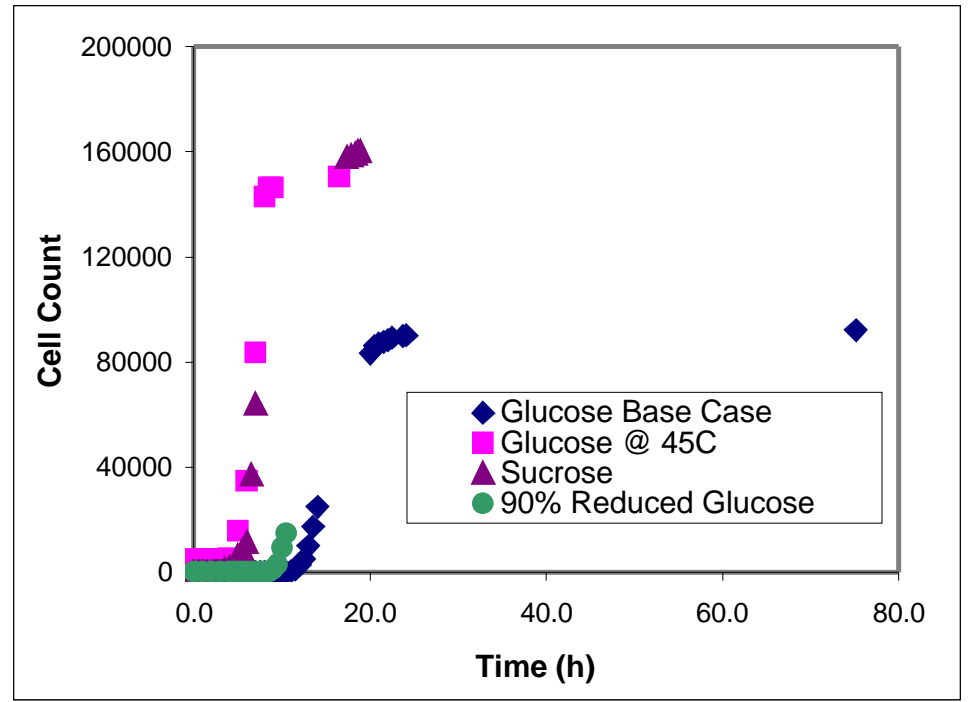

Figure A2. Sample Experimental Results from Cell Growth Experiments: Cell Counts in Lag, Exponential, Deceleration and Stationary Phases, as a function of Carbon Source, Concentration and Temperature.

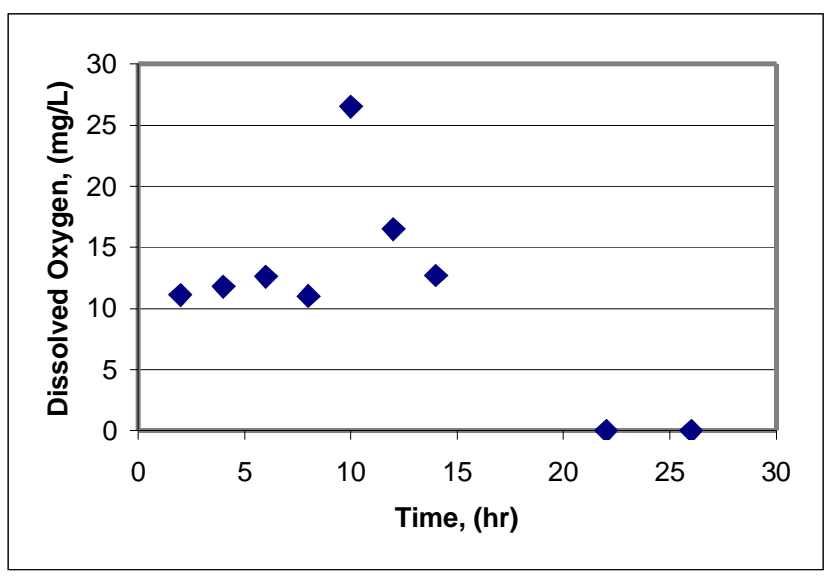

Figure A3. Dissolved Oxygen Content in Broth During Saccharomyces Cerevisae Fermentation on High Fructose Corn Syrup 


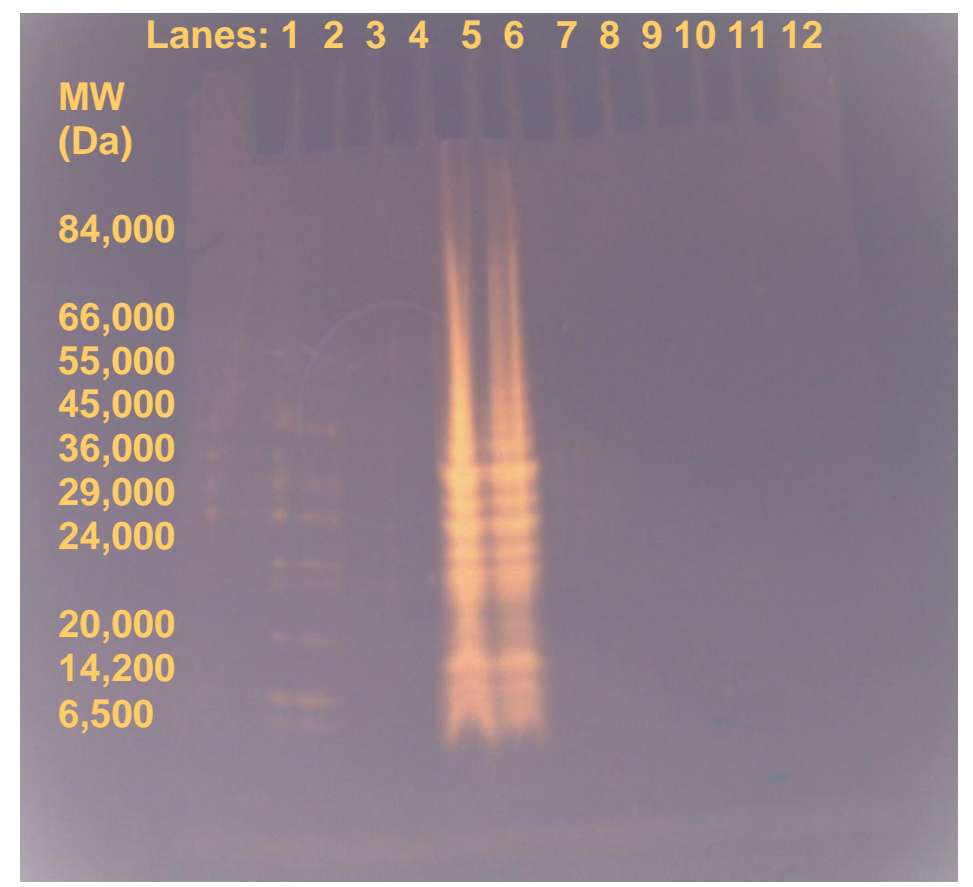

Figure A4. Sample Experimental Results for Electrophoretic Separation of Invertase at Different Stages of Purification 


\begin{tabular}{|c|c|}
\hline \multicolumn{2}{|c|}{ Table A1. Some Technical Writing \& Presentation Tips } \\
\hline \multicolumn{2}{|c|}{ WRITING } \\
\hline 1. Be Clear & use diagrams and sketches if possible to illustrate complex points \\
\hline 2. Cite references and sources & $\begin{array}{l}\text { document any ideas you take from other sources within the text. Even } \\
\text { websites are copyrighted. (MLA guidelines for bibliography format.) }\end{array}$ \\
\hline 3. Use trademarks & $\begin{array}{l}\text { if using tradenames, you must use appropriate notation: } \\
\text { Plexiglas }{ }^{\circledR} \text {, (consult a dictionary) or }{ }^{\mathrm{TM}}\end{array}$ \\
\hline 4. Proofread your work & $\begin{array}{l}\text { Finish early, set it aside, and reread before handing important reports to } \\
\text { managers or clients. }\end{array}$ \\
\hline 5. Spell check & $\begin{array}{l}\text { while spelling errors don't typically take away from the technical } \\
\text { content, they can turn off the reader. They can make large differences in } \\
\text { content, too- e.g., slight misspellings in pharmaceuticals }\end{array}$ \\
\hline $\begin{array}{l}\text { 6. Use a normal font, type } 10- \\
12 \text { size }\end{array}$ & make sure it is easily readable \\
\hline 7. Executive summary & $\begin{array}{l}\text { use an abstract on long reports which explains the whole content in } 1-2 \\
\text { paragraphs. Assume that this will be the only part read by management. }\end{array}$ \\
\hline 8. Survey the audience & $\begin{array}{l}\text { the language and style must match the people who will read the } \\
\text { document: businesspeople, engineers, 7th grade science class... }\end{array}$ \\
\hline 9. Use active voice & $\begin{array}{l}\text { it saves words and makes it more interesting for the reader } \\
\text { e.g., Tom presented. vs. The presentation was given by Tom. }\end{array}$ \\
\hline 10. Be brief & $\begin{array}{l}\text { it's hard to write short, but you must capture the attention of the } \\
\text { audience without losing them in wordy statements }\end{array}$ \\
\hline $\begin{array}{l}\text { 11. Avoid JARGON and } \\
\text { alphabet soup }\end{array}$ & $\begin{array}{l}\text { It's corporate nature to have acronyms to shorten long phrases that are } \\
\text { used repeatedly. Use the terms, if necessary, but define abbreviations } \\
\text { the first time they are used. e.g., Continuously stirred tank reactors, or } \\
\text { CSTRs, are used.... }\end{array}$ \\
\hline 12. Use Graphs and figures & but be sure that they are clear and cannot be misinterpreted. \\
\hline \multicolumn{2}{|r|}{ PRESENTATIONS } \\
\hline Use humor if appropriate & $\begin{array}{l}\text { it can help break tension in the audience, but don't rely on humor for } \\
\text { every slide }\end{array}$ \\
\hline Use 18 pt Font or LARGER & make sure that the words can be seen and read in the back of the room \\
\hline Discuss all points on a slide & $\begin{array}{l}\text { If you put something on a slide, it must be important. Discuss it. (or } \\
\text { leave it out to begin with) }\end{array}$ \\
\hline $\begin{array}{l}\text { Limit number of points on } \\
\text { each slide }\end{array}$ & $\begin{array}{l}\text { keep the presentation clean without jumbling up too much information } \\
\text { on any one slide. }\end{array}$ \\
\hline Use diagrams and figures & as they say, a picture can say 1000 words \\
\hline Speak clearly and slowly & people tend to speed up when in front of an audience- nervousness \\
\hline Practice & make sure you know what you are going to say \\
\hline 1 slide per minute & general guideline in preparing talks \\
\hline Show enthusiasm & $\begin{array}{l}\text { even if you're not overly excited by the topic, it can makethe } \\
\text { presentation much better received, and the audience will pay more } \\
\text { attention; this is a good way to avoid monotony. }\end{array}$ \\
\hline Spell check & again. \\
\hline Rehearse but don't memorize & $\begin{array}{l}\text { if you memorize the text of a presentation, then questions or other } \\
\text { events in the middle of your talk may derail the entire presentation }\end{array}$ \\
\hline Acknowledge & $\begin{array}{l}\text { mention people who helped in the project; the source of funding; } \\
\text { donated lab equipment, etc. }\end{array}$ \\
\hline Organize & make the slides flow so that your talk moves smoothly through points \\
\hline
\end{tabular}


Figure A5. Assessment Tool: Class Survey

\section{ChE 491 Class Survey}

1. Was the time commitment reasonable for the group experiments?

2. Did the experiments fit well with the theory from the 1st presentation?

3. Would you recommend other areas/ideas for project subjects?

4. What changes would you recommend based on the experimental part?

5. Was your group functional (did all members contribute)?

6. Part of the reason for doing the experiments in this way was to not follow an exact cookbook recipe and to make experimental design part of the engineering challenge to obtain results. Was this reasonable for a senior-level elective course?

7. Would you recommend this class to other students?

8. Rate the following in terms of how each of the learning methods was beneficial to you: ( $1=$ not helpful; 4 = best learning opportunity)

lectures

homework theory term paper group laboratory experiments in-class examples guest lectures in-class discussion links from website posted solutions to homeworks/exams

9. Any other comments? 